\title{
Most Frequent Musculoskeletal Manifestation of Systemic Lupus Erythematosus Patients in Dr. Hasan Sadikin General Hospital Bandung
}

\author{
Rahadian Nugi Sutrisno ${ }^{1}$, Andri Reza Rahmadi², Nita Novita ${ }^{3}$, Laniyati Hamijoyo²
}

\begin{abstract}
${ }^{1}$ Faculty of Medicine, Universitas Padjadjaran ${ }^{2}$ Division of Rheumatology, Department of Internal Medicine, Universitas Padjadjaran/Hasan Sadikin General Hospital ${ }^{3}$ Department of Forensic and Legal Medicine, Universitas Padjadjaran/Hasan Sadikin General Hospital
\end{abstract}

Corresponding author: Rahadian Nugi

Sutrisno, MD

Email: nugi rahadian@yahoo.com

\begin{abstract}
Background: Systemic Lupus Erythematosus

(SLE) is an autoimmune disease with wide range of clinical symptoms. The patients frequently complain musculoskeletal involvement during the active state of the disease. Musculoskeletal manifestation in SLE patients is an important sign in making early diagnosis and monitoring treatment response. This study aims to determine the presentation of musculoskeletal involvement of SLE patients in Dr. Hasan Sadikin General Hospital Bandung.

Methods: a descriptive cross-sectional quantitative study done by interviewing SLE patients concerning musculoskeletal manifestation as the primary data and tracking their medical record as the secondary data. Study was conducted between September to November 2016 in Rheumatology Clinic Dr. Hasan Sadikin General Hospital Bandung.
\end{abstract}

Result: Ninety-seven SLE patients, 91 females (93,81\%) and 6 males $(6,19 \%)$, were enrolled in this study with mean age $35.12( \pm 10.91)$ years. The three highest proportions of muskuloskeltal manifestations were arthritis of the knee $(84,5 \%)$, myalgia of upper back $(40,2 \%)$, and muscle weakness $(15,5 \%)$. We did not find any Jaccoud's Arthropathy (JA) and tendinitis manifestation. Osteoporosis were occured in 4 patients $(4,12 \%)$, whereas gout arthritis, spondytlitis, osteoarthritis, rotator cuff syndrome, and rhupus were only occured in one patient $(1,03 \%)$, respectively.

Conclusion: The common musculoskeletal manifestation in SLE patients were arthritis of knee, myalgia of upper back, and muscle weakness. Only small portion of patients suffered from osteoporosis, gout arthritis, spondytlitis, osteoarthritis, rotator cuff syndrome, and rhupus.

Keyword: musculoskeletal manifestation, musculoskletal involment, SLE

\section{Background}

Systemic Lupus Erythematosus (SLE) is an autoimmune disease that has wide clinical spectrum and organs involvement. The prevalence and incidence of SLE have been increasing in recent year. In Europe, North America, and South
America, the incidence of SLE was reported around 2 to 8 cases per 100.000 people per year. In USA, prevalence of SLE was reported in 51 cases per 100.000 people. In 2010, there were 291 SLE patients registered at Rheumatology Outpatient Department dr. Hasan Sadikin General Hospital Bandung. It was accounted for about $10,5 \%$ of all patients registered at Rheumatology Outpatient Clinic. The increase of SLE incidence in the last 40 years is implicated due to the invention of SLE diagnostic tools. ${ }^{1}$ Prevalence of SLE is six to ten fold higher in female than male. The prevalence was 128,7 cases per 100.000 people and incidence was 9,3 cases per 100.000 people. SLE prevalence was 2,3 fold higher in black people. ${ }^{2}$

Clinical manifestation of SLE involves joints, skin, kidney, lung, heart, central nervous system, and immune system. The wide clinical spectrum of SLE causes the difficulties in establishing the diagnosis. Further, patient's chief complaints are seldom specific. If the SLE patients get delayed therapy, disease activity may harm the patients. ${ }^{3}$

According to 10 years - research study conducted on 1.000 SLE patients in seven countries in Europe, the proper of most common SLE manifestation were athritis $(48,1 \%)$, malar rash $(31,1 \%)$, nephropathy $(27,9 \%)$, and photosensitivity $(22,9 \%){ }^{4}$ About 5 to 10 percent of SLE patient showed muscle enzymes elevation, include creatinine kinase, aminotransferase, aldolase, and lactate dehydrogenase. ${ }^{5}$ This explained that musculoskeletal manifestation in SLE patients had high occurrance.

The most prevalent musculoskeletal manifestation of SLE was arthritis, that marked by joint pain, effusion, and swollen joint of hand, wrist, and knee. ${ }^{5}$ Arthritis can significantly decrease patient's life quality. It make some disablities in daily activity, includes walking, climbing stairs, kneeling, and gripping fingers. The conditions may affect the psychosocial life of SLE patients. ${ }^{6,7}$ According to the research done at El Menia University Hospital, Egypt, avascular bone necrosis was occured in $15 \%$ of SLE patients. ${ }^{8}$ Several studies performed in Brazil reported, beside arthritis, $2.8 \%$ of SLE 
patients had Jaccoud's Arthropathy (JA) which marked by fingers and toes deformities, ${ }^{9}$ and about 95 percent of SLE patients complained general myalgia. ${ }^{10}$

Despite the high involvement of musculoskeletal, the data of musculoskeletal manifestations in SLE patients in Indonesia has not been documented. This study was designed to identify the musculoskeletal involvements of SLE patients at Dr. Hasan Sadikin General Hospital Bandung, Indonesia.

\section{Methods}

We used a descriptive cross-sectional study method. The primary data were obtained through interview with SLE patients about symptoms of the musculoskeletal system and the secondary data were obtained from medical records of patients. The study was conducted in Rheumatology Clinic Dr. Hasan Sadikin General Hospital Bandung from SeptemberNovember 2016. The minimum sample required in our study were 97 patients based on the formula for categorical and descriptive sample measurements that were taken consecutively. Samples included in the study were patients who have been diagnosed with SLE using ACR revised criteria, aged $\geq 14$ years, and registered as an outpatient. Patients whose medical records with incomplete identity and clinical condition reports were excluded in this study. Ethical clearance for this study has been received from the Commission on Health Research Ethics Faculty of Medicine, University of Padjadjaran with number 540 / UN6.C1.3.2 / KEPK / PN / 2016 and licence for this study has been received from Direktorat Jenderal Pelayanan Kesehatan Dr. Hasan Sadikin General Hospital.

All subjects got the explanation about the study and signed a consent form. Patient's demographic data (name, age, date of birth, occupation, address, and telephone number), duration of lupus, and the location of first diagnosis of SLE were obtained through interview. The interview results were recorded on a case report form (CRF). History of hypertension, trauma, infection, anemia, BMI, dyslipidemia, and definitive diagnosis of the musculoskeletal system were obtained through medical records of patients.

Data were collected and analyzed using Microsoft Excel 2013. Standard deviation for numerical data and percentages for categorical data were calculated

\section{Result}

There were 100 SLE patients met the inclusion criteria. One patient was excluded due to disagreement to join the study, two patients were excluded due to incomplete interview. Ninety-seven patients included as subjects in this study.

Mean age of subjects was 35,12 years (SD 10,103). There were $91(93,81 \%)$ females. The most prevalent group age was between $30-39$ years old $(34,02 \%)$. Among all samples, 63 patients $(64,95 \%)$ were housewife. Most patients (46,39\%) had been diagnosed as SLE for more than 5 years. There were 70 patients $(72,16 \%)$ lived in Bandung. Demographic data of SLE patients were presented in Table 1.
Table 1. Demographic Data of SLE Patients

\begin{tabular}{|c|c|}
\hline Characteristic & Data $(N=97)$ \\
\hline Mean Age (years) & $35.12 \pm 10.103$ \\
\hline \multicolumn{2}{|l|}{ Group age $(\mathrm{N}, \%)$} \\
\hline$\leq 15$ years & $1(1.03 \%)$ \\
\hline $16-19$ years & $2(2.06 \%)$ \\
\hline $20-29$ years & $29(29.89 \%)$ \\
\hline $30-39$ years & $33(34.02 \%)$ \\
\hline $40-49$ years & $24(24.74 \%)$ \\
\hline $50-59$ years & $7(7.21 \%)$ \\
\hline $60-69$ years & $1(1.03 \%)$ \\
\hline \multicolumn{2}{|l|}{ Gender (N,\%) } \\
\hline Male & $6(6.19 \%)$ \\
\hline Female & $91(93.81 \%)$ \\
\hline \multicolumn{2}{|l|}{$\mathrm{BMI}(\mathrm{N}, \%)$} \\
\hline Underweight & $9(9.27 \%)$ \\
\hline Normal & $73(75.25 \%)$ \\
\hline Overweight & $11(11.34 \%)$ \\
\hline Obese & $4(4.12 \%)$ \\
\hline \multicolumn{2}{|l|}{ Occupation $(\mathrm{N}, \%)$} \\
\hline Housewife & $63(64.95 \%)$ \\
\hline Employee & $15(15.46 \%)$ \\
\hline Enterpreneur & 7 (7.22\%) \\
\hline Student & $5(5.15 \%)$ \\
\hline Teacher & $4(4.12 \%)$ \\
\hline Health Worker & $1(1.03 \%)$ \\
\hline Housemaid & $1(1.03 \%)$ \\
\hline Unemployment & $1(1.03 \%)$ \\
\hline \multicolumn{2}{|l|}{ SLE duration $(\mathrm{N}, \%)$} \\
\hline$<1$ year & $17(17.52 \%)$ \\
\hline $1-3$ years & $16(16.49 \%)$ \\
\hline $3-5$ years & $17(17.52 \%)$ \\
\hline$>5$ years & $45(46.39 \%)$ \\
\hline Not Identified & $2(2.06 \%)$ \\
\hline \multicolumn{2}{|l|}{ Residency (N,\%) } \\
\hline Bandung & $70(72.16 \%)$ \\
\hline Non-Bandung & $27(27.83 \%)$ \\
\hline
\end{tabular}

According to the medical history which is presented in Table 2, 12 patients $(12.37 \%)$ have hypertension, 73 patients $(75.25 \%)$ had normal BMI, and four patients were obese. The most frequent of infectious disease from 2015 to 2016 was acute respiratory syndrome accounted for 11 patients (11.34\%).

Table 2. Medical History of SLE patients ( $\mathrm{N}=97)$

\begin{tabular}{lc}
\hline \multicolumn{1}{c}{ Medical History } & Results \\
\hline Hypertension (N,\%) & $12(12.37 \%)$ \\
Obesity & $4(4.12 \%)$ \\
Trauma & $1(1.03 \%)$ \\
Infectious Disease periode $2015-2016(\mathrm{~N}, \%)$ & \\
Acute Respiratory Syndrome & $11(11.34 \%)$ \\
Periodontitis & $8(8.24 \%)$ \\
Asymptomatic Bacteriuria & $8(8.24 \%)$ \\
Pulpitis & $5(5.15 \%)$ \\
Dental Caries & $5(5.15 \%)$ \\
Tuberculosis & $4(4.12 \%)$ \\
Tinea Corporis & $4(4.12 \%)$ \\
Gingivitis & $4(4.12 \%)$ \\
Urinary Tract Infection & $3(3.09 \%)$ \\
Herpes Zooster & $3(3.09 \%)$
\end{tabular}




\begin{tabular}{lc}
\hline \multicolumn{1}{c}{ Medical History } & Results \\
\hline Gastroenteritis & $3(3.09 \%)$ \\
Bronchitis & $3(3.09 \%)$ \\
Pneumonia & $2(2.06 \%)$ \\
Typhoid Fever & $1(1.03 \%)$ \\
Candidiasis & $1(1.03 \%)$ \\
Impetigo & $1(1.03 \%)$ \\
Hypercholesterolemia & $6(6.18 \%)$ \\
Anemia & $23(23.71 \%)$ \\
\hline
\end{tabular}

Among all samples, 96 patients had musculoskeletal involvement during disease activity and the manifestation were varied. There were 82 patients $(84.5 \%)$ had knee arthritis, 64 patients (66\%) had right fingers arthritis, and 61 patients $(62,9 \%)$ had left fingers arthritis. Presentation of arthritis in SLE patients are showed in Figure 1.

Figure 1. Arthritis in SLE patients ( $N=97)$

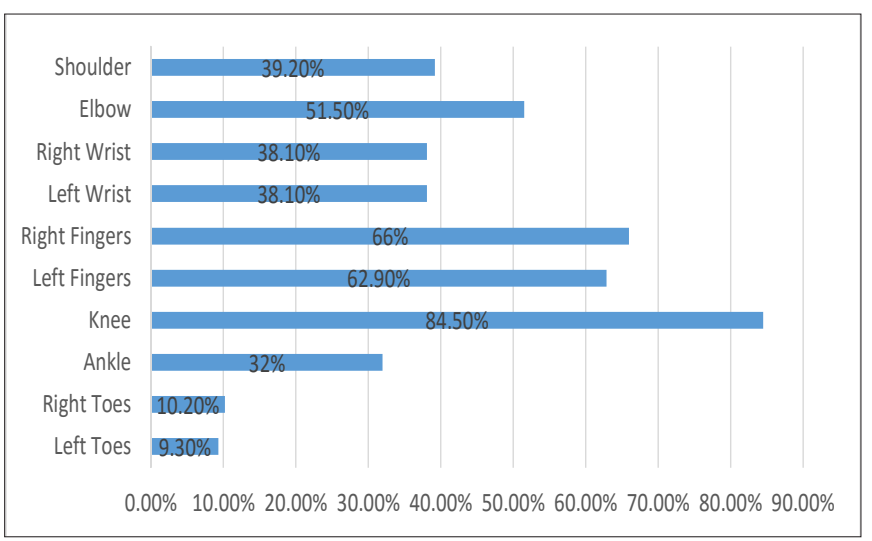

There were $39(40,2 \%)$ patients had myalgia in upper back, $37(38,1 \%)$ patients had myalgia in neck, and 31 (32\%) patients had myalgia in lower back. Myalgia manifestation of SLE patients are presented in Figure 2.

In this study, Jaccoud's Arthropathy and tendinitis were not found. Other musculoskeletal manifestation are presented in Figure 3.

Figure 2. Myalgia in SLE Patients

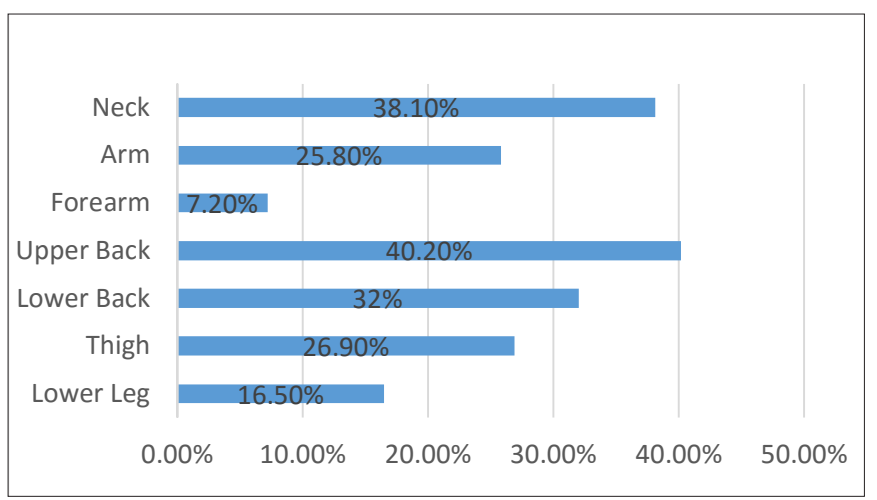

Figure 3. Other Musculoskeletal Manifestation in SLE Patients

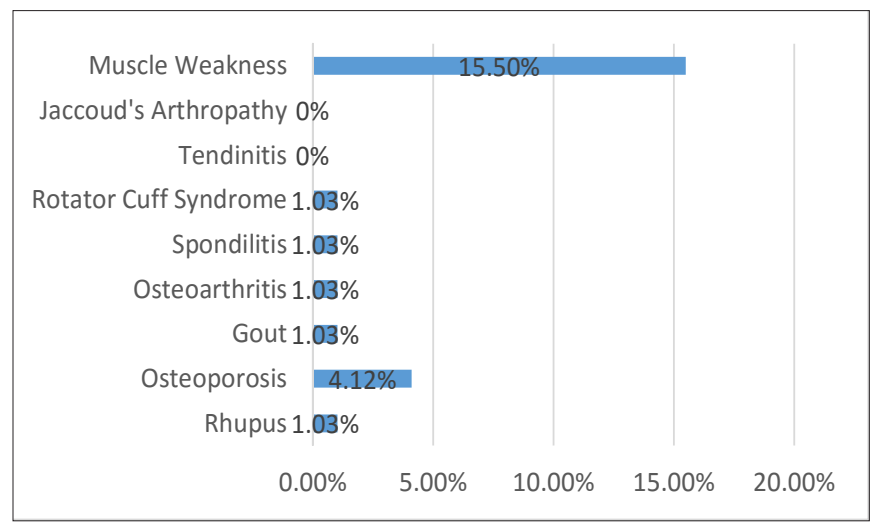

\section{Discussion}

In this study, demographic data showed that female's prevalence was higher than male's, this is consistent with study done by Julia F. Simard et al., stated the prevalence of SLE in Sweden on 2010, were 144 in females per 100.000 SLE cases a year and only 25 in males per 100.000 SLE cases; ${ }^{11}$ Also accordance with the epidemiology study of SLE patients in America which is six fold higher in females than males. ${ }^{12}$ It is suggested due to higher leptin level found in females than in males. Leptin is known could induce autoantibody and inhibit immune regulation. ${ }^{13,14}$

SLE was more frequently found in patients ranged from 30 to 39 years old. This condition is caused by the higher level of esterogen in reproductive age. Estrogen could cause disregulation of immune system. Therefore, SLE is nine fold more frequent in reproductive-aged females than in males with the same age. ${ }^{15}$

InfectioninSLEwaslikelycausedbytheimmunosuppressant drugs used for controlling disease activity. Infections may induce the flare in SLE. This is caused by molecular mimicry of immune system stimulates autoimmunity by cross-reactive process of immune system and self-antigen. Infection of Herpes virus, Retrovirus, and RNA virus could induce this reaction. Furthermore, infection caused by Candida albicans, Staphylococcus aureus, Salmonella, and Escherichia coli are more frequent in SLE and cause flare. ${ }^{16}$ In this study, etiology of infectious diseases are not listed in medical record so the comparison of infectious agents could not be presented.

In our study, we found 82 patients $(84,5 \%)$ had knee arthritis, 64 patients $(66 \%)$ had arthritis of right fingers, and 61 patients $(62,9 \%)$ had arthritis of left fingers. Arthritis may occur in almost all joints of SLE patients. This finding is similar with Smith PP, et al. study ${ }^{17}$, which stated that in SLE, arthritis could manifest in all joints with knee involvement was the highest proportion. This is nearly similar to article written by Manole Cajacaru et al., that stated arthritis in SLE frequently affect toes, wrist, and knee. ${ }^{18}$ High level of cytokine is correlated with SLE disease activity level and arthritis manifestation. Cytokine induction resulted from 
the deposition of antigen-antibody complex may activate complement system in high filtration area, such as joints and kidneys. ${ }^{5,19}$

Myalgia of upper back occured in $40.2 \%$ SLE patients, myalgia of neck occured in $38.1 \%$ patients, and myalgia of lower back occured in $32 \%$ patients. This result concordants with study conducted by A Zoma, which found myalgia in $40-80 \%$ of SLE patients during flare state. ${ }^{20}$ Muscle ache in SLE is related to the activation of complement system by antigen-antibody complex deposition which is similar to patophysiology of arthritis. This complement activation ultimately induces inflammation in muscle tissue. ${ }^{5}$

Jesscia L, et al. reported myositis were found in $55 \mathrm{SLE}$ patients aged $9-21$ years old in Southeast America, 31\% of 55 myositis patients had proximal muscle weakness and muscle enzyme elevation, such as creatinine kinase, AST, aldolase, and LDH. ${ }^{21}$ The report is dissimilar with our study result. We only found $15,5 \%$ of SLE patients complained muscle weakness. The differences were possibly occured due to the fewer of total sample used in previous study than in our study and the difference of sampling technique used. In the other hand, Joseph Font, et al., study found lower rate of muscle weakness in SLE patients, which were found only in $7 \%$ of 600 SLE patients. ${ }^{22}$ These distinct results are probably due to total samples used in Joseph F,et al study is higher than in our study despite the same level of disease activity.

There were not any Jaccoud's Arthropathy (JA) cases found in this study. This is inconsistent with previous study done by Thelma L Skare et al., who found $6,17 \% \mathrm{JA}$ in SLE patients. ${ }^{23}$ The dissimilarity is probably caused by the difference characteristic of study sample and the amount of samples used between the studies. However, we had same level disease activity among the samples joined in the research. Tendinitis, as a cause of JA, was also not found in our study. This is contradicted with previous study by T.Ogura et al., who concluded that tendinitis was more frequent in SLE than Rheumatoid Arthritis. ${ }^{24}$ This difference may occur due to the lack of data in medical record and no subjective data regarding tendinitis was obtained.

Osteoporosis were found in $4(4,12 \%)$ SLE patients. The result is consistent with review-article conducted by GarcíaCarrasco M, et a.l that found osteoporosis in 4.0-48.8\% SLE patients. ${ }^{25}$ Osteoporosis in SLE is related to low osteocalcin level, the habits to avoid UV light may influence vitamin-D level. Furthermore, the adverse effect of corticosteroid used for long period may also play roles. ${ }^{25}$ Our study found only one SLE patient with spondilitis. This conclusion is similar to literature review written by Figen $\mathrm{T}$, et al. that conclude spondilitis as a rare condition among SLE patients. ${ }^{26}$

Study done by Tani C. et $a l^{27}$ found $10(9,7 \%)$ of 103 SLE patients with RA, or Rhupus, at Rheumatology Unit of Pisa University Italy. This percentage was slightly higher than our study $(1,03 \%)$. Despite the same sampling technique, the length of period and amount of sample used in Tani C, et al was wider than our study.
The limitation of the study is the comparison among variables could not be done due to lack of article discusses the same topic, especially in Indonesia. Researcher interpretation to musculoskeletal symptoms could cause bias.

\section{Conclusions}

The most common musculoskeletal manifestations in SLE patients were knee arthritis and myalgia of the upper back muscles. Patients with symptoms of muscle weakness were low compared to other studies. JA manifestation and tendinitis were not found in this study. Osteoporosis was the most common other musculoskeletal manifestation compared to spondylitis, rhupus, osteoarthritis, rotator cuff syndrome, and gout.

Further studies should be conducted on a multicharacteristic of populations in Indonesia with a cohort study design so that the clinical pictures of patients with SLE are more accurate. Longer period of the study is needed to include more subjects.

\section{Reference}

1. Bertsias G, Cervera R, Boumpras D. Systemic lupus erythematosus: pathogenesis and clinical features. Eular On-line Course Rheum Dis. 2012;(1909):476-505.

2. Somers E, Marder W, Cagnoli P, Lewis E, DeGuire P, Gordon C, et al. Population-based incidence and prevalence of systemic lupus erythematosus. Arthritis Rheumatol. 2014;66(2):369-378

3. Kasjmir Y, Handono K, Wijaya LK, Hamijoyo L, Albar Z, Kalim H, et al. Rekomendasi perhimpunan reumatologi Indonesia untuk diagnosis dan pengelolaan lupus eritematosus sistemik. 2011: 1-54 .

4. Cervera R, Khamashta MA, Font J, Sebastiani GD, Gil A, Lavilla P, et al. Morbidity and mortality in systemic lupus erythematosus during a 10 Year period a comparison of early and late manifestations in a cohort of 1.000 patients. Mortality. 2003;82(5): 299-308

5. Navara SV, Torralba TP. The musculoskeletal system and bone metabolism. In : Dubois' lupus erythematosus and related syndromes, $8^{\text {th }}$ ed. Wallace Daniel J, Hanh Bevra H, editors. Philadelphia: Elsevier Saunders;2013: 333-40

6. Beckerman N, Auerbach C, Blanco Irene. Psychosocial dimension of SLE: implication for the health team. J Multidiscip Healthc. 2011;4:63-72

7. Backman C. Arthritis and pain, psychosocial aspect in the management of arthritis pain. Arthritis Res Ther. 2006;8(6):221.

8. Ghaleb RM, Omar GM, Ibrahim MA. Avascular necrosis of bone in systemic lupus erythematosus. Egypt Rheumatol. 2011;33(1):27-33.

9. Ball EMA, Bell AL. Lupus arthritis-do we have a clinically useful classification?. Rheumatology. 2012;51(5):771-9.

10. Lam NVU, Ghetu M V, Bieniek ML, Luke S. Systemic lupus erythematosus: primary care approach to diagnosis and management. Am Fam Physician. 2016;94(4):284-94.

11. Simard JF, Sjöwall C, Rönnblom L, Jönsen A. Systemic lupus erythematosus prevalence in Sweden in 2010: what do national registers say ? Arthritis Care Res. 2014;66(11):1710-17.

12. Feldman CH, Hiraki LT, Liu J, Fischer MA, Solomon DH, Winkelmayer WC, et al. Epidemiology and sociodemographics of systemic lupus erythematosus and Lupus nephritis among US adults with medicaid coverage. Arthritis and Rheumatism. 2013;65(3):753-63.

13. Lourenço E V, Liu A, Matarese G, La A. Leptin promotes systemic lupus erythematosus by increasing autoantibody production and inhibiting immune regulation. Proc Natl Acad Sci USA. 2016;113(38):10:637-42. 
14. Wahrenberg H, Hruska K, Reynisdottir S, Arner P, Hellstro L. Mechanisms behind gender differences in circulating leptin levels. J Intern Med. 2000;247(4):457-62.

15. Pierdominici $M$, Ortona E. Estrogen impact on autoimmunity onset and progression : the paradigm of systemic lupus Erythematosus. Int Trend Immun. 2013;1(2):24-34.

16 Perl A, Francis L. Infection in systemic lupus erythematosus: friend or foe. Int J Clin Rheumatol. 2010;5(1):59-74

17. Smith PP, Gordon C. Autoimmunity reviews systemic lupus erythematosus : clinical presentations. Autoimmun Rev. 2010;10(1):435.

18. Hospital C, Sciences B. Manifestations of Systemic Lupus Erythematosus. Maedica. 2011;6(4):330-36.

19. Ball EMA, Gibson DS, Bell AL. Plasma IL-6 levels correlate with clinical and ultrasound measures of arthritis in patients with systemic lupus erythematosus. Lupus. 2014;23(1):46-56.

20. Zoma A. Musculoskeletal involvement in systemic lupus erythematosus. Lupus. 2004;13(11):851-3.

21. Record JL, Beukelman T, Cron R0. High prevalence of myositis in a southeastern United States pediatric systemic lupus erythematosus cohort. Pediatr Rheumatol Online J. 2011;9:201-6.
22. Font J, Cervera R, Ramos-casals $M$, Garcı M, Herrero C, Olmo J, et al. Clusters of clinical and immunologic features in systemic lupus erythematosus: analysis of 600 patients from a single center. Semin Athritis Rheum. 2004;33(4):217-30.

23. Skare TL, Godoi Ade L, Ferreria Vo. Jaccoud arthropathy in systemic lupus erythematosus : clinical and serological findings. Rev Assoc Med Bras 2012;58(4):489-92.

24. Ogura T, Hirata A, Hayashi N, Takenaka $S$, Ito $H$, Mizushina K, et al. Comparison of ultrasonographic joint and tendon findings in hands between early, treatment-naive patients with systemic lupus erythematosus and rheumatoid arthritis. Sage J. 2016;1-8.

25. García-carrasco M, Mendoza-pinto C, Escárcega R0, Jiménez-hernández M, Etchegaray I, Pt M, et al. Osteoporosis in patients with systemic lupus erythematosus. Isr Med Assoc J .2009;11 (8):486-91.

26. Tarhan F, Argın M, Can G, Özmen M, Keser G. Coexistence of systemic lupus erythematosus and ankylosing spondylitis: another case report and review of the literature. Eur J Rheumatol. 2014;1(1):39-43.

27. Tani C, Aniello DD, Sedie AD, Carli L, Cagnoni M, Possemato N, et al. Autoimmunity Reviews Rhupus syndrome : Assessment of its prevalence and its clinical and instrumental characteristics in a prospective cohort of 103 SLE patients. Autoimmun Rev. 2013;12(4):537-41. 